\title{
El largo camino hacia la verdadera independencia judicial: de la Revolución francesa a nuestros días - una historia de utopías, mitos y realidades-
}

Juan Luis Gómez Colomer*

\section{Resumen}

El texto consigna una importante reflexión acerca de la autonomía del Poder Judicial, a cuyo efecto toma como marcos de referencia a Colombia y España; se advierte que, si bien, existe cierta independencia del sector Judicial, ésta ha sido sometida y superada por el poder Político, lo cual lleva a su autor a cuestionarse si ese cometido es un mito o una realidad. De esta manera, se busca identificar las garantías sobre las cuales deben edificarse los sistemas judiciales, para lograr una separación real entre la política y la justicia, con énfasis en una clara división de poderes.

\section{Palabras Clave}

Administración de justicia, comunidad autónoma, democracia, división de poderes, Estado de Derecho, independencia judicial, poder judicial, poder ejecutivo, poder político, soberanía.

\section{Introducción}

"Sois inamovibles en vuestro cargo, porque sois responsables de vuestros actos". Esta frase, atribuída al jurista liberal español Eugenio Montero Ríos, quien fue Ministro de Gracia y Justicia a finales del siglo XIX y Presidente del Gobierno a principios del

\footnotetext{
* Texto de la conferencia impartida por el autor en la inauguración de la VI Cohorte de la Maestría en Derecho, Línea de Derecho Procesal Penal, codirigida por él y el Profesor Fernando Velásquez, en la Universidad Sergio Arboleda, Bogotá (Colombia), el día 28 de febrero de 2014.
} 
siglo $\mathrm{XX}$, pone el dedo en la llaga y reitera como indiscutible, que responsabilidad e independencia judicial, caminan juntas; ambas, constituyen uno de los pilares esenciales del funcionamiento imparcial del Poder Judicial, así como una de las bases de la Democracia, pues sin jueces justos no hay Estado de Derecho. La evolución de su práctica nos lleva, sin embargo, a cuestionarnos si estaremos ante una utopía o ante un mito; porque la realidad se desmiente cada día, prácticamente en todo el mundo. Permítanme exponerles en el tiempo concedido unas reflexiones al respecto.

\section{La utopía: ¿Qué es la independencia judicial?}

De independencia judicial en sentido aprehensible por la ciudadanía, hoy únicamente puede hablarse a partir de la Revolución Francesa (1789). Lo que se trataba en aquel entonces, como hoy, era ubicar al nuevo juez en el nuevo Estado, o lo que es lo mismo, al Poder Judicial como tercer poder del Estado; según la aceptada y ejercida concepción del Barón de la Bréde en la Democracia, acorde con los principios que la sostienen.

No es difícil en este sentido, dar un concepto de independencia judicial admisible universalmente, si se atiende al ideario revolucionario francés. Aunque las soluciones propuestas en ese país se corresponden, como es lógico, con un determinado momento histórico; de ahí la relatividad con que deban contemplarse. El problema es más bien otro, a saber, analizar cómo se ha desarrollado y desarrolla ese concepto y sobre todo, cómo se ha practicado en los países que para nosotros constituyen un referente jurídico de primer orden, como también en aquellos en que vivimos y se desarrolla nuestra actividad profesional.

El Estado democrático moderno, se organiza políticamente por decisión libre de sus ciudadanos, distribuyendo sus potestades de gobierno en tres poderes: El Poder Ejecutivo (Administrativo o Político), el Poder Legislativo y el Poder Judicial, que ocupa el tercer lugar. España y Colombia han seguido este modelo al pie de la letra.

Sin embargo, pensar que el Poder Judicial estuvo y que se mantiene, al mismo nivel que los otros dos poderes, es desconocer la realidad; es algo inalcanzable ahora. En suma, es una utopía, porque los poderes verdaderamente importantes fueron, son y serán, el Poder Ejecutivo y el Poder Legislativo, en este orden. 
A pesar de lo anterior, si existe el Poder Judicial es por algo, y esa degradación cualitativa que ha sufrido y sufre no debería estar justificada. ¿De dónde surge el concepto Poder Judicial? la explicación es histórica y debemos mirar de nuevo hacia la Revolución Francesa: al establecerse políticamente el principio de la división de poderes, se quiso determinar con exactitud quién era el titular de la soberanía, para garantizar la libertad del ciudadano frente al poder absoluto, lo cual, implicó deslindar la función de legislar de las funciones de gobernar y de juzgar.

En ese momento histórico y en ese país (Francia), originariamente se pensaba que el Poder Judicial, sería un instrumento eficaz para acabar con la monarquía absoluta; a partir de la defensa de la libertad y mediante la aplicación de la ley. Como bien lo ejemplifica la famosa frase del propio Montesquieu (1995, p. 77), el juez es la boca que pronuncia las palabras de la ley.

Sin embargo, ¿Cómo se configuró el Poder Judicial inicialmente? Pues, ciertamente, no como un verdadero poder del Estado, sino como un falso poder; no equiparable a los demás, porque se partió de una gran desconfianza hacia los tribunales. De ahí que se atribuyera su titularidad, en un principio, al pueblo, quien elegía a sus Jueces por un tiempo. Con ello, se logró realmente que el Poder Ejecutivo se apoderara del Poder Judicial (con Napoleón); considerándose que juzgar era parte de gobernar. El Poder Judicial se tornó así sólo en una administración como otra cualquiera; la Administración de Justicia.

La Revolución Francesa muestra claramente, que el Poder Judicial, configurado con propósitos de controlar a los otros dos poderes, fue rápidamente absorbido por el Poder Político -nada proclive a ser controlado, y menos por un poder no elegido democráticamente-. Estas ideas, también pasan a España a lo largo del siglo XIX, otorgándose al Juez, de manera adicional, la consideración de funcionario administrativo; permitiéndose que fuera movible fácticamente por el Ministro de Justicia de turno (Ley Orgánica del Poder Judicial, 1870). Ello influyó en América, porque ésa es precisamente la época de mayor influencia legislativa Española en el Nuevo Mundo.

Desde cierta perspectiva y con estas bases, comienza en el siglo XX una importante lucha del Poder Judicial por el mantenimiento de la potestad inherente a él, independiente del Poder Ejecutivo y Judicial. Al mismo tiempo, comienza otra, no menos importante 
lucha, de sus miembros por la propia identidad, negándose a denominarse servidores públicos como los demás, afirmando su propia independencia frente a todos los ciudadanos. La bandera de su existencia deja de ser nacional, para convertirse en la bandera de la independencia; la única que garantizará su subsistencia.

¿Qué hubo de hacerse en ese proceso de cambio para conseguir que el Poder Judicial fuera un verdadero Poder? Hacer que el Poder Político, presionado la mayor parte de las veces por los agentes sociales, creyera en él, proclamando formalmente que existe un Poder Judicial y regulándolo como tal. Se le deja, entonces, al mismo nivel que el Poder Político y Legislativo; como un verdadero tercer Poder del Estado. Esto únicamente sucede en mi país, España, tras la Constitución democrática de 1978, que sienta las bases del gran cambio frente a la dictadura Franquista.

En Colombia el advenimiento de la Democracia, implica las mismas tendencias, convirtiéndose la Constitución Política de 1991 y la Ley Estatutaria de la Administración de Justicia de 1996, en las manifestaciones más claras en este sentido.

El punto de partida fue fijar el concepto de poder político (del Estado), como aquel que se deriva de la soberanía, para explicar cómo, el Poder Judicial, es parte del mismo y cómo se relaciona con los otros poderes del Estado, lo cual sólo tiene sentido dentro del Estado democrático.

Es necesario resaltar, que no basta con la concepción formal de Democracia, sino que debe existir además, una cultura democrática y una creencia cívica en su viabilidad, atendiendo su propio valor. La realidad muestra que los ataques a la independencia judicial son constantes y letales, también, en las democracias más consideradas. Estamos volando dentro de turbulencias apreciables, en ciertos casos con tramos insoportables; algunos, parece que las justifican expresamente frente al terrorismo y el crimen organizado, argumentando que el Estado debe defenderse como sea de los enemigos. Otros callan y luego asienten, aceptando con normalidad que haya menos garantías procesales. Mal camino en ambos casos: pues, acecha el mal.

Si se mantiene una postura autoritaria o de asentimiento tácito, uno de los principios que inmediatamente se resiente es el de la independencia judicial, porque al Estado sólo interesan jueces activos políticamente en su defensa. Jueces sin rostro, apolíticos 
(pero en verdad los más politizados), premiados con ascensos y altas responsabilidades.

En su concepción revolucionaria francesa, la independencia es advertida como el principio garante de que el juez, únicamente, estará sometido a la ley a la hora de resolver el conflicto o imponer la pena. Sin embargo, este concepto se mantiene poco tiempo porque se quiere controlar políticamente esa aplicación de la ley.

En la actualidad, constitucionalmente la independencia judicial, es un principio subjetivo del poder judicial que aísla a sus miembros en el cumplimiento de su función, de los demás poderes. La verdadera independencia sigue implicando quedar sometido únicamente a la ley; como lo advierten tanto la Constitución Española $^{1}$-que lo proclama directamente-, como la Constitución Colombiana. Esta última, en su artículo 228, utiliza la formulación indirecta, anticuada y confusa de decisiones independientes de la Administración de Justicia; y en el artículo 230 dispone mucho más certeramente que: "los jueces, en sus providencias, sólo están sometidos al imperio de la ley"2.

\section{El mito: El juez no es un ser aislado}

En el mundo del Derecho Procesal nos estamos acostumbrando a que ciertos principios, máximas, reglas esenciales o valores, se conviertan por diferentes razones en un mito. El mito es la atribución a alguien, o a algo, de una cualidad o excelencia que no tiene; ejemplos en lo procesal, sería el principio de oralidad, o la misma presunción de inocencia. ¿Es la independencia judicial en ese sentido un mito también?

En el Poder Judicial, el juez, es el encargado constitucionalmente de aplicar la ley; cuando resuelve los conflictos jurídicos de los ciudadanos o impone la pena que corresponde al delito cometido. Para un correcto ejercicio de esa función, se requiere cierto aislamiento, no sólo de carácter subjetivo; rodeándolo de aquellas garantías que más refuercen su independencia, sino también objetivo; enmarcándolo en una concepción democrática del Estado, que favorezca su suprema posición decisora del conflicto o de la pena.

Esta posición de aislamiento, de vivir en una burbuja que prevenga de cualquier infección, no es generalmente soportable por el Poder Político, el cual, solamente en una democracia sana y fuerte, 
puede ser obligado (con garantías) a respetar absolutamente al Poder Judicial -ante cuyo desconocimiento queda sujeto a sanciones gravísimas, que pueden hacerle tambalear e incluso caer-. En las democracias débiles, el Poder Judicial es el que primero sucumbe, porque es el más moldeable, el mejor controlable y el menos poderoso en definitiva.

El Poder Político es sutil, no suele ser, en una democracia, amigo de enfrentamientos directos por el control de los otros dos poderes del Estado. Para controlar al Poder Judicial, históricamente se ha valido de dos instrumentos muy efectivos: negar la existencia de una verdadera carrera judicial y negar la inamovilidad judicial.

Esos dos instrumentos han atacado directamente al Juez independiente, responsable e imparcial, porque el ciudadano que sea juez o que desee serlo, sabe que determinados puestos únicamente podrá ocuparlos durante un período de tiempo determinado y que su plaza nunca estará segura; ya que podrá ser trasladado a otro lugar o a otro órgano jurisdiccional inferior. Por ello, aunque constitucionalmente la independencia judicial implique quedar sometido únicamente a la ley, no debe traer como consecuencia que el juez quede aislado o marcado socialmente por serlo.

Frente a las posibles agresiones del Poder Político indicadas, las democracias sólidas suelen establecer, al máximo nivel legal, una serie de garantías que le protejan y hagan viable. De lo contrario sería muy fácil convertir el concepto de Poder Judicial en mero papel mojado. El inconveniente es que no todas las democracias regulan la carrera judicial, como si lo hacen España y Colombia (Ley Estatutaria de la Administración de Justicia, 1996, art. 156-175)³.

Esas garantías, de amplio reconocimiento internacional, presentan variantes y matices en cada país, como es lógico, pero persiguen lo mismo: proteger al juez cuando juzgue y mantener su independencia. Suelen distinguirse diversas garantías y, sólo por el tiempo concedido, me detengo en las más importantes:

- El legislador constitucional establecen en primer lugar una serie de garantías frente a los demás poderes del Estado, de manera tal que el Poder Judicial se encuentra en una posición ideal para cumplir con sus funciones. Así, por ejemplo, la ley prohíbe que se puedan dictar reglamentos interpretativos de las leyes por las cortes supremas. 
Otra garantía en esta línea, es que ni el Gobierno, ni la Administración, ni el Poder Legislativo, ni entidad pública alguna, puedan dictar instrucciones que regulen el Poder Judicial, ni mucho menos condicionar sus decisiones mediante actuaciones concretas. En Colombia existe esta garantía en el artículo 5 de la Ley Estatutaria de la Administración de Justicia, el cual prevé en su párrafo que: Ningún superior jerárquico en el orden administrativo o jurisdiccional podrá insinuar, exigir, determinar o aconsejar a un funcionario judicial para imponerle las decisiones o criterios que deba adoptar en sus providencias.

Así mismo, con mayor fuerza normativa, el artículo 257.3 de la Constitución Política, contiene una previsión que puede ser peligrosa, y es que el Consejo Superior de la Judicatura tiene como una de sus funciones, la de dictar los reglamentos necesarios para el eficaz funcionamiento de la administración de justicia; relacionados con la organización y funciones internas asignadas a los distintos cargos y la regulación de los trámites judiciales y administrativos que se adelanten en los despachos judiciales, en los aspectos no previstos por el legislador (Véase. Ley Estatutaria de la Administración de Justicia, 1996, art. 85).

Derivando lo anterior, en un control político o político-judicial del Poder Judicial, a consecuencia del cual no hay independencia.

- También, en segundo lugar, frente a la propia ley hay garantías: Toda la materia procesal debería aprobarse mediante ley y no permitir reglamentos, ni de la Corte Suprema, ni de nadie (en América es frecuente lo contrario, por ciertas vicisitudes históricas en las que no puedo entrar). Sin embargo, también hay matices, singularidades, que permiten cierta flexibilidad interpretativa; siempre conveniente para adaptar estas graves cuestiones a las peculiaridades de cada país. El problema, es que algunos de ellos pueden afectar a la independencia y sus garantías, lo cual conlleva a que el sistema se pueda derrumbar y los jueces de un país dejen de ser independientes. Por ello, en mi opinión, debe haber los siguientes mínimos intocables:

- Establecimiento de una verdadera carrera judicial (sin ella la independencia no está en absoluto garantizada), lo que implica una regulación legal muy clara del ingreso, permanencia, ascenso, suspensión y jubilación de los jueces y magistrados dentro del escalafón judicial. La clave está en el ingreso, porque si no se establecen 
criterios objetivos que demuestren la capacidad y mérito del aspirante, el peligro de nepotismo (nombramiento de familiares, de amigos y de los inquebrantables del gobernante) es más que evidente. Un sistema de concurso-oposición, en el que el candidato a juez, además de sus méritos, ingrese por sus conocimientos jurídicos, es siempre bien recibido.

En Colombia, estos temas son controlados por el Consejo Superior de la Judicatura, sin que se pueda decir que exista una verdadera carrera judicial en términos comparatistas europeos (Constitución Política de Colombia, 1991, art(s). 255 y 256). En el país, los jueces de ingreso son generalmente egresados de Facultades de Derecho que aprueban una oposición (evaluaciones) y un curso de formación judicial (Ley Estatutaria de la Administración de Justicia, 1996, arts. 160, 164 y 168). Los magistrados de apelación y de la Corte Suprema tienen normas especiales (Constitución Política, 1991, arts. 231 y 232).

- Ausencia de decisión política en la atribución de los puestos para la magistratura más elevada, (tribunales de apelación, tribunales de casación y cortes supremas).

Este aspecto resulta muy común en América Latina, lo cual representa un serio inconveniente para la afirmación positiva de la independencia judicial. Limitar, por ejemplo, a ocho años el período dedisfrute del cargo de Magistrado de la Cámara oSala (Civilo Penal), de la Corte Suprema, como ocurre en Colombia, sin posibilidad además de reelección (Constitución Política de Colombia, 1991, art. 233), y además hacer depender ese nombramiento de la respectiva corporación, a partir de unas listas enviadas por el Consejo Superior de la Judicatura (Constitución Política de Colombia, 1991, art. 231), no sólo es excluyente, sino que aumenta el riesgo de politización de los elegidos. Los nombramientos puede que ya no dependan de sus méritos y capacitación, sino de sus relaciones políticas.

- Establecimiento de un régimen de incompatibilidades claro e indubitado (v.gr., prohibición de ser abogado al mismo tiempo).

- Regulación de las prohibiciones en igual forma: por ejemplo, el juez no puede pertenecer a un partido político.

Tanto en este caso como en el anterior, se trata de ser más que la mujer del César, de manera tal que, en general o para el caso concreto, quede excluido el juez sobre el que recaigan determinadas 
circunstancias objetivas o subjetivas que puedan perjudicar suimagen independiente e imparcial. Los ejemplos puestos son significativos. El problema no es establecer en la norma esas incompatibilidades y prohibiciones ${ }^{4}$, sino hacerlas realmente efectivas cuando surjan o se manifiesten. Por ejemplo, el juez no puede pertenecer a un partido político.

- Disfrute de un salario digno, desde los niveles iniciales de la judicatura.

Éste es el principal problema, (aunque no insalvable) porque un juez bien pagado tiene tendencia a no corromperse. Sin embargo, la mayoría de los países no son ricos, o están inmersos claramente en crisis económicas prolongadas y duraderas, lo que impide salarios altos. Es necesario entonces, hacer un esfuerzo por mejorar la situación económica, sobre todo de los jueces de ingreso, porque la independencia judicial lo exige.

Con todo, la protección más importante es la inamovilidad judicial. Esto, porque garantiza que sentencien lo que sentencien, los jueces, únicamente podrán ser trasladados, suspendidos, expulsados o jubilados de la carrera judicial, por las causas previstas legalmente -entre las que nunca estará, la de no ser simpático o dócil al poder ejecutivo o legislativo-.

En caso de existir un órgano de gobierno de los jueces en un país, como ocurre en España, o en Colombia con el Consejo Superior de la Judicatura (previsto en la Constitución Política, en los artículos 254 a 257); la ley garantiza la inamovilidad precisamente frente a sus decisiones. Lo que implica que el consejo judicial correspondiente no puede, por ejemplo, irrumpir ilegalmente en el ejercicio de la función jurisdiccional para trasladar o suspender al juez porque las decisiones de este, no agradan al Poder Político. El artículo 152.5 de la Ley Estatutaria de la Administración de Justicia (1996), establece como uno de los derechos del juez colombiano, el de: "Permanecer en su cargo mientras observe buena conducta, tenga rendimiento satisfactorio, no haya llegado a la edad de retiro forzoso, y en las demás circunstancias previstas en la ley". Más claro y terminante, habría sido proclamar sin ambages la inamovilidad judicial como principio garante de la independencia.

En caso de no existir en el país un órgano como el mencionado anteriormente, la inamovilidad, legalmente consagrada, opera frente 
a todos los Poderes del Estado en función de la injerencia sufrida. Sin embargo, la extensión de esa inamovilidad varía de país en país. Algunos, aunque la reconocen expresamente, en realidad la vulneran en sus propias normas o la desconocen en la práctica. Colombia no la respeta en su órgano judicial ordinario más importante; aunque sí en la justicia de instancia. La Corte Suprema de Justicia, como indicamos supra, limita su mandato a ocho años (Constitución Política de Colombia, 1991, art. 233). Establecer una duración temporal del cargo judicial es un severo correctivo del principio de inamovilidad, pues en esencia la está negando. El juez, no por ello es un ser aislado de la sociedad en que vive, sino protegido, que es muy distinto.

\section{La realidad: El poder de juzgar es el más importante}

¿Qué está sucediendo en la práctica? ¿Cuál es la realidad sobre la independencia? En mi opinión, el poder de juzgar es el más importante de los tres poderes del Estado. Porque sin jueces verdaderamente independientes, no hay democracia.

Las claves del Poder Judicial en una democracia, deben ser la independencia y la imparcialidad anexa a ella, así como la responsabilidad; constituyendo las anteriores, las dos caras de la misma moneda. Recordando la frase inicial, de que los jueces son independientes porque son responsables, permite afirmar que la independencia y la responsabilidad son así reconocidas, en casi todas las constituciones democráticas.

Con estos supuestos, se pretende asegurar que el juez al decidir, será justo, objetivo e imparcial; que se cumplirá ese anhelo, tan respetable de todo justiciable, de que quien decida su caso reúna esas cualidades. El juez, tiene que ser ajeno al conflicto que se somete a su decisión.

Ahora, cabe una precisión de carácter internacional: sabedor el constituyente de la fortísima posición pública que puede significar en la realidad social un Poder Judicial independiente, lo instituye constitucionalmente responsable, pero esto no es una mera declaración retórica, sino que se establecen tres clases de responsabilidad, atinentes a lo siguiente:

- La disciplinaria, en caso de cometer el juez un ilícito administrativo (exigible administrativamente, pero el juez no es un funcionario, al menos no es el típico funcionario). 
- La civil, en caso de responsabilidad civil del juez por daños causados dolosa o culposamente al ejercer la función jurisdiccional (exigible jurisdiccionalmente por esa vía).

- La penal por haber cometido el juez delito en el ejercicio de sus funciones (también exigible jurisdiccionalmente pero en la vía penal, en muchos países con una protección previa que opera como filtro para excluir actuaciones vengativas, como era el caso de España hasta 1995, o lo es ahora el de Guatemala, de acuerdo con el art. 206 de su Constitución Política de 1993). En otros países la garantía de protección se supone que consiste en el enjuiciamiento por órganos que en realidad no son jurisdiccionales, por ejemplo, en Colombia, pues los magistrados de la Corte Suprema, entre otros altos cargos, son enjuiciados por el Congreso de la República (arts. 116. II de la Constitución Política y 178 de la Ley Estatutaria de la Administración de Justicia).

En Colombia, la potestad disciplinaria frente a los jueces, la tiene el Consejo Superior de la Judicatura (Ley Estatutaria de la Administración de Justicia, 1996, art. 256.3).

La verdad, sin embargo, es que este diseño teórico de la independencia, admisible por todos en principio, no existe como tal en la realidad práctica, o todavía no hemos llegado a que el poder de juzgar sea ejercido verdaderamente por jueces independientes al cien por ciento.

En la mayor parte de los países, el juez tiene más de funcionario administrativo que de miembro de un poder independiente del Estado. Por ello, los ataques a su independencia son más fáciles y frecuentes. Citaré algunos ejemplos de ello, todos muy graves:

- Nombramiento político (por el Poder Ejecutivo, por el Poder Legislativo, o por ambos, o por el Poder Ejecutivo, el Legislativo y el Poder Judicial conjuntamente) de los jueces inferiores (ingreso controlado en la carrera judicial, como ocurre en Colombia con los altos cargos judiciales, art. 231 de la Constitución, a cargo de corporaciones que los nombran de listas remitidas por el Consejo Superior de la Judicatura).

- Control político (por los mismos poderes del Estado) del ascenso (o juez de apelación).

- Nombramiento político de los miembros de la Corte Suprema de Justicia. 
- Cambios de destino jurisdiccional efectuados discrecionalmente sin sujeción a norma alguna, muchas veces con una clara vulneración del principio del juez legal o juez ordinario predeterminado por la ley 5 .

Todo lo anterior, implica en realidad que no haya una separación nítida entre Política y Justicia; pues en esos casos la carrera judicial (si existe), aparenta ser sólo una variante de la carrera política del magistrado, y si no existe, parece el camino o trampolín ideal para algo mejor. La consecuencia lógica de ese sistema, no debe ser otra que, para ascender y progresar dentro del escalafón judicial, hay que ser un juez sumiso y obediente.

\section{Un ejemplo de los problemas expuestos: La opción político- legislativa española por la independencia judicial}

Para que vean que el diseño de la independencia y responsabilidad judicial, no es una entelequia intelectual de un investigador encerrado en su despacho, sino algo muy real, les hablaré ahora de lo que pasó en España. Esto último, cuando hubo que abordar, al terminar la dictadura y empezar la democracia, la regulación del juez como Poder Judicial en el nuevo sistema; el cual, presenta una particularidad espectacular al afrontar el tema de la independencia judicial desde una perspectiva absolutamente novedosa.

En efecto, una de las decisiones más importantes que debió adoptar la clase política española en el tránsito de la dictadura a la democracia (1975-1978), fue la de dotar de singularidad política y jurídica a las diferentes realidades y sensibilidades existentes en España. Lo anterior, no sólo con reconocer legalmente todos los partidos políticos de claro origen y finalidad democráticas -e integrarlos en la ardua tarea de transitar adecuadamente hacia la plena democracia-, sino también (y esto es más importante de lo que parece a la vista de la evolución que se ha producido), reconocer explícitamente y encauzar en un nuevo modelo de Estado, los territorios, históricos o no, pero que tradicionalmente han conformado España desde finales del siglo XV; denominados reinos, principados, marquesados, condados, o simplemente regiones o provincias, algunos con más peso que otros, pero todos ellos claramente identificados.

Esta última decisión, dio origen a la reserva en la Constitución democrática de 1978, título XVIII, artículos 137 a 158, ambos inclusive. El título, comprende todo un texto dedicado a la nueva confi- 
guración política de los territorios, que unidos conforman España y que pasaron a denominarse comunidades autónomas. Sin perjuicio de otras disposiciones dispersas en la propia Constitución, que hacen referencia política o jurídica a ellas.

En total son diecisiete comunidades (más dos ciudades autónomas). Cada una con sus particularidades propias, pero con el común denominador de disponer de los mínimos instrumentos políticos, jurídicos, sociales y económicos necesarios para desarrollarse y contribuir con ello a la mejora y progreso del Estado de España, sin la cual ni se entienden, ni tiene sentido su existencia jurídica.

Ese complejo entramado normativo que la Constitución diseña, parte de esa idea central, consensuada y apoyada por todos los partidos políticos de representación nacional en esos momentos. El mencionado título, establece, tras la formulación de unos principios generales y unas pocas reglas dedicadas a la Administración local, las normas básicas por las que se rigen las comunidades autónomas.

Establecida la base (el común denominador), el pensamiento fundamental del legislador constituyente fue que la comunidad autónoma se tradujera, desde el punto de vista organizativo, en un reflejo del Estado, si no idéntico, al menos bastante parecido. Adicionalmente, se autorizó en dicha comunidad, la constitución de un poder legislativo y de un poder ejecutivo propios (Constitución Española, 1978, art. 152). No se quiso, sin embargo, el cumplimiento cabal de la división de poderes de Montesquieu (referida al inicio de esta intervención), porque las comunidades autónomas no tienen un poder judicial propio. El poder judicial en España es único (Constitución Española, 1978, art. 117.5).

Este hecho indiscutible; esa realidad jurídica irrefutable, constituye una de las cuestiones clave del principio de la independencia judicial y su observancia en la práctica, a la vista de este diseño político del Estado en España.

Así, una pregunta inicial debemos hacernos inmediatamente, una vez constatada la inexistencia de poderes judiciales propios en las comunidades autónomas: ¿Por qué no quiso el legislador constituyente español (de 1978) que las comunidades autónomas tuvieran un poder judicial propio? No olvidemos que el negar dicho poder en la comunidad autónoma, fue un hecho indiscutido en su momento y que la amplísima mayoría que obtuvo el Sí, 
en el referéndum del día 6 de diciembre de 1978 (más del $88 \%$ de los votantes), demostró indubitadamente que eso era lo que querían los españoles, independientemente de los detalles en que se pueda discrepar legítimamente. Lo esencial de la propuesta de Constitución, y por tanto la inexistencia de poderes judiciales autonómicos, fue aceptado como tal sin discusión.

Pues bien, en mi opinión, la razón fundamental por la que se estimó no conveniente la existencia de un poder judicial propio en las comunidades autónomas, no fue ni jurídica, ni de otra índole, v.gr., económica o social, sino política, sólo que con enormes consecuencias jurídicas. La razón política está unida a la decisión, también constitucional, de que España fuese y sea un estado no federal, sin ser, tampoco, un estado centralista, sino un estado intermedio avanzado, al menos más sólido políticamente que otros estados que se organizan en regiones (Italia) o departamentos (Francia), más proclive a instituciones de corte federal que de cariz centralista, ciertamente, pero no totalmente federal. La innovación que suponía esta nueva vía política, implicó tomar decisiones excluyentes en su momento, es decir, hubo que optar por renuncias, por prohibiciones y por variantes. La más importante exclusión fue y es, precisamente, la concepción unitaria del estado en la configuración de su poder judicial.

Sin embargo, lo anterior, sólo explica la forma y no el fondo de la cuestión. Aún, aceptándose que la razón por la cual el diseño constitucional excluyó al poder judicial autonómico, fue por pensarse que los tribunales propios de las autonomías no encontraban acomodo en un estado no federal (modelo que políticamente fue desechado), la pregunta esencial sigue en pie: ¿Por qué se excluyó al poder judicial, y no a cualquiera de los otros dos, o a los dos, rebajándose la calidad del gobierno?

Esta segunda pregunta, como su respuesta, nos permite entrar de lleno en el objeto de nuestro análisis: la independencia judicial. De igual manera, permite reflexionar sobre el por qué estamos ante un tema tan candente hoy. No se previó entonces; y si se hizo no tuvo consecuencia alguna, que el desarrollo del estado, gracias al progreso de las autonomías, un día u otro llevaría a la formulación de la pregunta anterior, es decir, que la ciudadanía, y sobre todo sus representantes políticos, se acabarían cuestionando de alguna manera, acerca del por qué una comunidad autónoma no puede disponer, también, de un poder judicial propio. 
Varias respuestas pueden darse a esta cuestión, pero después de tantos años estudiando la Constitución, explicando a mis alumnos la parte general del Derecho Jurisdiccional, e investigando sobre temas de Derecho Procesal de trascendencia en todos los procesos; sean civiles o penales, sólo me satisface una, y no es del todo convincente, como intentaré demostrar, por su carácter relativo. Las comunidades autónomas, en mi modesta opinión, no disponen de un poder judicial propio, porque en España después de una larga dictadura, se pensó en el momento histórico de la transición democrática y elaboración de nuestra constitución actualmente vigente, que era la decisión más apropiada para garantizar la independencia judicial; absolutamente necesaria para lograr, cuanto antes, la plena democratización.

\section{Sin jueces verdaderamente independientes no hay democracia.}

Esa contestación requiere varias matizaciones en aspectos de gran impacto jurídico. Esto, con el fin de que en el futuro se pueda garantizar un desarrollo no sólo equilibrado, sino también (sobre todo) justo del principio constitucional de la independencia judicial, lo que redundará sin duda alguna, en beneficio del propio estado y de las comunidades autónomas.

Permítanme recordar una afirmación que ya he hecho ante Ustedes, que no por obvia debe dejarse a un lado: La independencia judicial es claramente un principio político de naturaleza jurisdiccional orgánica en una democracia, sin duda alguna, pero no es una cuestión territorial, ni de un estado ni de un territorio de ese estado, sino un pilar básico para que el proceso sea justo, se celebre en donde se celebre y se desarrolle, en cualquiera de sus fases, en donde se desarrolle. La forma del estado no es lo importante. El único presupuesto para que su aplicación sea plenamente eficaz es que el estado sea una democracia. Da igual si es un estado federal, centralista, regionalista o autonomista. Sin el Estado de Derecho, la independencia judicial es una verdadera quimera.

La Constitución española (dejamos conscientemente fuera la Ley Orgánica del Poder Judicial y las leyes procesales particulares) proclama el principio de la independencia judicial en varios preceptos $^{6}$, configurándola como uno de los pilares básicos de la nueva democracia española, surgida después de 1978.

Por tanto, la cuestión esencial es que sin independencia judicial, ni puede existir un proceso debido, un proceso justo, o un proceso 
con todas las garantías, ni puede existir un verdadero Poder Judicial, ni en definitiva puede desarrollarse la propia democracia.

La independencia judicial es un principio político predicable del conjunto orgánico jurisdiccional. No sólo de un juez individual o de un grupo de tribunales, porque, aun predicable únicamente de los jueces y magistrados, su concurrencia afecta a todos los actos procesales que se celebren desde el principio hasta el final del proceso (actos cuyos destinatarios principales son las partes del proceso).

Estas ideas, forman parte esencial de la cultura jurídica del mundo más avanzado política, legal, social y económicamente a fecha de hoy. Tanto el sistema continental (países de civil law), como el anglosajón (países de common law), hacen de la independencia judicial uno de los pilares básicos del sistema de Justicia.

\section{El Estado, garante inicial y final de la independencia judicial.}

La cuestión central, entonces, es determinar si es admisible que las comunidades autónomas no tengan un poder judicial propio, en razón a la idea de que sólo el Estado es capaz en estos momentos de garantizar la independencia judicial. El Estado, garantiza la independencia judicial, insistimos, el pilar esencial para que el proceso, cualquiera (especialmente el civil y el penal), sea ajustado al Estado de Derecho, de varias maneras y a través de diversos modelos, como lo muestra el Derecho comparado.

Se ha hecho alusión al Estado unitario, es decir, al principio de la unidad jurisdiccional. Esa es la principal opción española: no es posible constitucionalmente que en nuestro país exista más de una potestad jurisdiccional, sólo hay una, y la posee el Estado por atribución expresa de la soberanía popular. Como consecuencia de ello, la potestad jurisdiccional es en España indivisible, de manera que todos los tribunales, desde el juez de paz del lugar más recóndito y pequeño, hasta la Sala I del Tribunal Supremo, la poseen en su totalidad. Por eso, nuestra Constitución dice que el principio de la unidad jurisdiccional es la base de la organización y funcionamiento de los tribunales (Constitución Española, 1978, art. 117.5).

Esta es la opción, que en su momento se consideró como la mejor para garantizar la independencia judicial. Sin embargo, no sólo se configuró el principio de la unidad jurisdiccional con ese fin, sino que también, derivadamente, se articuló en nuestra norma suprema 
un Poder Judicial y una organización judicial únicos para todo el Estado, así como un estatuto jurídico común para todos los jueces y magistrados. Además, se dio un catálogo de garantías concretas de la independencia judicial, entre las que debe destacarse especialmente la inamovilidad; donde reside una de las claves esenciales, que tiene su fundamento constitucional en España igualmente (Véase Constitución Española, 1978, art. 117.1).

Esto es posible, entre otras cosas, porque la Constitución tomó paralelamente la decisión de que la legislación procesal orgánica, y también la procesal civil y procesal penal, fuesen de competencia exclusiva del Estado (1978, art. 149.1-5 y $6^{\mathrm{a}}$ ). De tal manera que las comunidades autónomas no pueden legislar sobre esta materia, con la salvedad que mencionaremos enseguida.

En la unidad jurisdiccional, reside, pues, la clave de bóveda de todo el sistema para garantizar su sostenibilidad, en pro de la independencia judicial. No hay otra explicación posible: Al existir otras opciones, y dado que los privilegios de los fueros empezaron a desaparecer efectivamente a finales del siglo XIX, el legislador constituyente la consideró la única vía en ese momento histórico para que todos los jueces españoles, unidos por ese principio, fuesen y se sintiesen verdaderamente independientes en el ejercicio de la función jurisdiccional.

En la propia elaboración de la Constitución resultó evidente, sin embargo, que negar a las comunidades autónomas un Poder Judicial propio no iba a resultar, en lo político, absolutamente indiscutido y asumido por todos sin oponerse. Es por ello, que el propio texto constitucional fija en diferentes preceptos un mínimo de participación de las comunidades autónomas en la organización del Poder Judicial, que no en el ejercicio de la potestad jurisdiccional. El problema, es que lo ha hecho de tal manera que, en vez de fijar la posición política de manera clara e irrefutable, ha sembrado dudas, incluso contradicciones, que han abierto sin desearlo, nuevas vías polémicas para mantener viva la llama sin cerrar el interrogante, que las comunidades autónomas (mucho más atentas que el Estado) han aprovechado hábilmente. Por eso, se ha forzado a que el máximo intérprete de nuestra Constitución, el Tribunal Constitucional, tome partido al firmar decisiones que no debería haber adoptado nunca, creando todavía más polémica.

Lo que ha resuelto nuestro Tribunal Constitucional era algo obvio y, gustara o no gustara, no debía causar sorpresas; porque 
entraba dentro de las interpretaciones posibles, aunque haya sido ciertamente restrictiva, en el sentido de que no avanza en el desarrollo del estado autonómico. En esencia, lo que se ha dicho respecto a la participación de las comunidades autónomas en el Poder Judicial único, es que aquellas no pueden aportar mucho para garantizar la independencia de los jueces y magistrados que ejercen la función jurisdiccional en su territorio (es decir, la función de juzgar y hacer ejecutar, lo juzgado, del Poder Judicial español; a lo que llama núcleo duro de la administración de justicia). Aunque sí pueden -y deberían- ayudar, a que dicho trabajo se realizara, por quienes han sido legitimados constitucionalmente para ello, de manera más cómoda y agradable ${ }^{7}$.

Esta decisión, aunque poco afortunada en la nomenclatura -sobre todo porque en España no cabe hablar en democracia ya nunca más de Administración de Justicia, pues la Justicia no es un tema del Gobierno, del Poder Político, sino de Poder Judicial-, es sostenible jurídicamente en lo esencial, si se leen con detenimiento los preceptos afectados. A pesar de ello, no es evidentemente, una decisión atrevida, o que busque una mayor implicación en el estado de la comunidad autónoma; que es uno de los problemas políticos más graves que tenemos en la actualidad. No es en definitiva una decisión a favor de la comunidad autónoma, razón por la cual, en vez de cerrar la polémica, la ha abierto todavía más, dejando heridas graves e importantes en el camino.

Con el fin de redondear la estructura organizativa, la Constitución consagró también un órgano autónomo multifuncional, especialmente diseñado para lograr una práctica efectiva de la independencia judicial. El Consejo General del Poder Judicial, igualmente único para todo el Estado -Constitución Española, 1978, art. 122-, no es un órgano jurisdiccional, sino un órgano constitucional; cuya misión principal es gobernar administrativamente en forma autónoma todos los juzgados y tribunales españoles que conforman el Poder Judicial ordinario ${ }^{8}$. Aunque su composición, inicialmente, se pensó que fuera técnica, objetiva e independiente de los partidos políticos; la realidad actual es que, es un órgano que recoge en sus límites la composición política del parlamento de turno, lo cual, indubitadamente vulnera el espíritu de la Constitución en ese punto.

Pues bien, respecto al principio de la independencia judicial, me parece claro que el diseño que se articula en nuestra Constitución es el siguiente: en su vertiente subjetiva, la independencia es un 
principio personal de todos los jueces y magistrados de España, en el ejercicio de la función jurisdiccional al aplicar las leyes, el cual, se protege también personalmente, mediante el establecimiento de ciertas garantías (inamovilidad principalmente). En su vertiente objetiva, se crea el Consejo General del Poder Judicial, para que, como órgano de autogobierno, proteja institucionalmente a todos los jueces y magistrados frente a los demás poderes del Estado; en particular, frente a intromisiones del poder ejecutivo, ayudado del Ministerio fiscal -otro órgano constitucional que debe velar por la independencia de los tribunales, según la propia Constitución-.

El Estado, es pues, el único garante de la independencia judicial en la actualidad política española así entendida, y, las comunidades autónomas, ningún papel pueden jugar en ello. Aunque, la realidad nos ha mostrado varias veces que este diseño no es ya aceptable, porque ha quedado anticuado ${ }^{9}$. Este tema, sin embargo, excede de la cuestión esencial que quería transmitir en este análisis y, por ello, no lo voy a tratar.

\section{Conclusión}

Obviamente, no hay un único modelo de organización del Poder Judicial. Cada país, atendidas sus razones históricas, su cultura y su forma política, es libre de escoger aquél que más convenga a sus intereses. Lo único que se exige con carácter previo, es que ese país sea una democracia formal y real; donde todos los modelos deben respetar unos mínimos, si quieren ser aceptados como manifestaciones de un Poder Judicial verdaderamente independiente.

No pienso en ningún país concreto. He realizado un sondeo de Derecho comparado para preparar esta conferencia teniendo en cuenta varios modelos; muchos de ellos de América Latina. He pretendido formular un diseño abstracto. En muchos países se dan algunos de los problemas indicados. Colombia no es una excepción.

Si queremos efectiva independencia, empecemos por lo verdaderamente importante. Debemos articular, si no lo tenemos o perfeccionarlo si lo poseemos, con fundamento en la Constitución política democrática:

- Una verdadera carrera judicial (y lo mejor sería que los nombramientos judiciales fuesen hechos objetivamente por el propio Poder Judicial, respetando la capacidad y mérito de los candidatos). 
- Una auténtica inamovilidad, garantizando la protección legal máxima para el juez frente a agresiones de los tres poderes del Estado.

\section{Notas}

1 La Constitución española, artículo 117.1, proclama directamente la independencia judicial al reconocer que los integrantes del poder judicial son independientes e inamovibles, y que se encuentran sometidos únicamente al imperio de la ley.

2 Véase, Ley Estatutaria de la Administración de Justicia en Colombia, artículo 5; que es más directo y moderno: “La Rama Judicial es independiente y autónoma en el ejercicio de su función constitucional y legal de administrar justicia".

3 En ellos se prevé una Ley de Carrera Judicial que hasta la fecha no ha sido aprobada.

4 Colombia lo hace en el artículo 232 de la Constitución y más detalladamente en los artículos 125 y 147 a 155 de la Ley Estatutaria de la Administración de Justicia.

5 Véase, Ley Estatutaria de la Administración de Justicia en Colombia, artículo 152.5, que permite cambios de destino judicial por no observar el juez buena conducta o rendimiento satisfactorios; que son conceptos demasiado peligrosos.

6 Constitución Española, art(s). 117.1, 117.2, 124.1 y 127.2, entre otros.

7 Los aspectos materiales y de recursos humanos no judiciales, a los que se llama la administración de la Administración de Justicia.

$8 \quad$ Los regulados en la Ley Orgánica del Poder Judicial de 1985.

9 El caso del Magistrado Garzón sobre la Ley de Memoria Histórica, uno de los tres que se incoaron contra él, lo ha puesto a prueba recientemente en España. En el Auto de 3 de febrero de 2011 resolutorio del incidente de recusación en la llamada causa Crímenes de la Guerra Civil y de la Dictadura de Franco, la Sala Especial del Tribunal Supremo, constituida al amparo del art. 61 de la Ley Orgánica del Poder Judicial, tomó la decisión importante a instancias de Garzón de apartar por falta de imparcialidad nada menos que a toda una Sala, al haber quedado contaminada a través de los recursos de los que no había tenido más remedio que conocer contra resoluciones del instructor, también magistrado del TS al ser Garzón

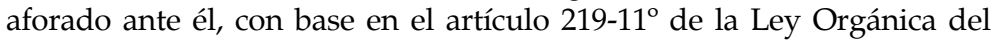
Poder Judicial citada, dándole la razón. El conocido magistrado español fue absuelto finalmente en este proceso penal. 
Lo impactante a nuestros efectos es la falta de respuesta legal para resolver este tema cuando se plantea un incidente de recusación para tutelar la independencia judicial ex novo en el Tribunal Supremo, ya que la contaminación con las actuales reglas parece inevitable, y además, lo que es mucho más grave, que nada menos que cinco magistrados del órgano judicial más importante de España, más el instructor, sean recusados por falta de independencia judicial habiendo negado inicialmente cinco de ellos la causa (el otro la admitió y se abstuvo directamente).

\section{Referencias}

Cardozo, B. N. (1996). La función judicial. Atizapán de Zaragoza. México: Ed. Pereznieto.

Constitución Política (1991). Congreso de la República de Colombia. Colombia.

España. Constitución de España. (1978). Reino de España. España.

Fairén, V. (1969). La figura del Juez. En V. F. Guillén. Temas del Ordenamiento Procesal. T. I. Madrid: Ed. Tecnos.

Fairén, V. (1983). La independencia judicial en España en la actualidad. En V. F. Guillén. Estudios de Derecho Procesal Civil, Penal y Constitucional. T. I. Madrid: Edersa.

Gómez, J. L. (2012). Independencia judicial y diseño político del Estado. En J. L. Gómez Ed. El Derecho Procesal español del siglo XX a golpe de tango (Juan Montero Aroca. Liber Amicorum, en homenaje y para celebrar su LXX cumpleaños. Valencia: Ed. Tirant lo Blanch.

González, P. (1993). Independencia del Juez y control de su actividad. Valencia: Ed. Tirant lo Blanch.

Hernández, V., (1991). Independencia del Juez y desorganización judicial. Madrid: Ed. Civitas.

Ibáñez, P. y Movilla, C. (1986). El Poder Judicial. Madrid: Ed. Tecnos.

Ley 270 de 1996. Ley Estatutaria de la Administración de Justicia. Congreso de la República de Colombia, marzo de 1996.

Montero, J. (1990). Independencia y responsabilidad del Juez. Madrid: Ed. Civitas.

Montero, J. (1999). Sobre la imparcialidad del Juez y la incompatibilidad de funciones procesales. Valencia: Ed. Tirant lo Blanch.

Montero, J.; Gómez, J. L.; Montón, A. \& Barona, S. (2013). Derecho Jurisdiccional I. Parte General. 21 a ed. Valencia: Ed. Tirant lo Blanch. 
Santaella, M. (1995). Montesquieu el legislador y el arte de legislar. Madrid: Ed. Gráf. Ortega.

Simon, D. (1985). La independencia del Juez. Barcelona: Ed. Ariel.

Taruffo, M. (2009). La cultura de la imparcialidad en los países del Common Law y del Derecho continental. En C. Gómez. Ed. La imparcialidad judicial, Estudios de Derecho Judicial (151). Madrid: Ed. Consejo General del Poder Judicial y Escuela Judicial. 